\title{
Prevalence of the Janus kinase 2 V617F mutation in Philadelphia-negative myeloproliferative neoplasms in a Portuguese population
}

\author{
ANA PAULA AZEVEDO ${ }^{1,2}$, SUSANA N. SILVA ${ }^{1}$, ALICE REICHERT ${ }^{3}$, \\ FERNANDO LIMA ${ }^{3}$, ESMERALDINA JÚNIOR $^{2}$ and JOSÉ RUEFF ${ }^{1}$ \\ ${ }^{1}$ Centre for Toxicogenomics and Human Health (ToxOmics), Genetics, Oncology and Human Toxicology, \\ NOVA Medical School, Faculty of Medical Sciences, NOVA University of Lisbon, 1169-056 Lisbon; \\ Departments of ${ }^{2}$ Clinical Pathology and ${ }^{3}$ Clinical Hematology, Hospital of São Francisco Xavier, \\ West Lisbon Hospital Centre, 1449-005 Lisbon, Portugal
}

Received May 9, 2017; Accepted July 7, 2017

DOI: $10.3892 /$ br.2017.977

\begin{abstract}
Myeloproliferative neoplasms (MPNs) result from the malignant transformation of a hematopoietic stem-cell (HSC), leading to abnormal amplification and proliferation of myeloid lineages. Identification of the Janus kinase 2 (JAK2) V617F mutation developed the knowledge of Philadelphia-negative (PN)-MPNs, contributing to and influencing the definition of the phenotype and prognostic impact. Considering the lack of Portuguese epidemiological data, the present study intends to characterize the prevalence of the JAK2 mutation in a PN-MPN versus a control Portuguese population. Caucasian Portuguese PN-MPN patients $(n=133)$ and 281 matched control subjects were investigated. No significant differences were identified between the case and control groups concerning age distribution or smoking habits. Pathology distribution was as follows: $60.2 \%$ with essential thrombocythemia (ET), $29.3 \%$ with polycythemia vera (PV) and $10.5 \%$ with primary myelofibrosis (PMF). A total of $75.0 \%$ of patients were positive for the presence of the JAK2 V617F mutation. In addition, the prevalence of PV was 87.2\%, ET was $73.4 \%$ and PMF was $50.0 \%$. The JAK2 V617F mutation is observed in various MPN phenotypes, and has an increased incidence in ET patients and a decreased incidence in PV patients. These data may contribute to improving the knowledge of the pathophysiology of these disorders, and to a
\end{abstract}

Correspondence to: Dr Susana N. Silva or Professor José Rueff, Centre for Toxicogenomics and Human Health (ToxOmics), Genetics, Oncology and Human Toxicology, NOVA Medical School, Faculty of Medical Sciences, NOVA University of Lisbon, 130 Campo dos Mártires da Pátria, 1169-056 Lisbon, Portugal

E-mail: snsilva@nms.unl.pt

E-mail: jose.rueff@nms.unl.ptt

Key words: Philadelphia-negative myeloproliferative neoplasms, Janus kinase 2 mutation, Portugal more rational and efficient selection of therapeutic strategies to be adopted, notably because most of the patients are JAK2 V617F negative.

\section{Introduction}

Myeloproliferative neoplasms (MPNs) are clonal disorders resulting from the malignant transformation of hematopoietic stem cells (HSCs), leading to abnormal amplification and proliferation of one or more myeloid lineages. According to the World Health Organization (WHO) 2008 classification and the 2016 revision $(1,2)$, the classic MPNs encompass chronic myelogenous leukemia and the BCR/ABL-negative disorders (Philadelphia-negative MPNs; PN-MPNs), such as polycythemia vera (PV), essential thrombocythemia (ET) and primary myelofibrosis (PMF). Less frequent MPNs are chronic neutrophilic leukemia, chronic eosinophilic leukemia and other unclassifiable entities $(1,2)$.

Among the various registries worldwide, the PN-MPNs have a combined annual incidence rate of 0.4-2.8 (while the literature estimated 0.68-2.6) for PV, 0.38-1.7 for ET and 0.1-1.0 for PMF, per 100,000 respectively $(3,4)$.

The presence of clonal hematopoiesis and cytokine hypersensitivity are fundamental for distinguishing PN-MPNs from reactive conditions. In routine practice, clonality is usually determined by the presence of an acquired mutation or cytogenetic abnormality, although additional clinical, laboratory and morphological information is important in the diagnosis of each specific subtype (5-7).

Clinically, PV is characterized by excessive production of erythrocytes, increased red cell mass and extramedullary hematopoiesis, leading to splenomegaly. In ET there is a high platelet count, often associated with thrombotic and hemorrhagic events; however, bone marrow fibrosis is the hallmark of PMF, resulting in a variable count of myeloid series cells and hepatosplenomegaly $(1,2,8)$.

Major genetic insights into the pathogenesis of the PN-MPNs include identification of the somatic point gain-of-function mutations in the Janus kinase 2 (JAK2) 
gene (9-13), myeloproliferative leukemia (MPL) virus oncogene (more frequently termed $\mathrm{W} 515 \mathrm{~L} / \mathrm{K}$ ), and recently calreticulin (CALR) mutations, which contributed to an improved understanding of the pathophysiology of these disorders, their diagnostic tools and therapeutic management (9-13). According to the available studies, the frequencies of these mutations are $\sim 95,0$, and $0 \%$ in PV, 60, 3, and 20\% in ET, and 60, 7, and $25 \%$ in PMF, respectively $(6,14-18)$. Although it is possible to identify one of these mutations in the majority of the BCR/ ABL-negative disorder patients, there are unidentified genetic defects in approximately $10-15 \%$ of cases, predominantly of ET and PMF and, furthermore, those mutations cannot fully explain the phenotypic heterogeneity of PN-MPNs nor the susceptibility of progression to myelofibrosis, acute myeloid leukaemia (AML) or myelodysplastic syndromes (MDS) (16). In addition, the cellular and molecular mechanisms involved in the pathophysiology of MPNs have not yet been fully clarified (16,19-26).

It is well known that hematopoietic cytokine receptor signaling is largely mediated by JAKs, a family of tyrosine kinases, and their downstream transcription factors, termed signal transducer and activator of transcription (STAT). JAK2 is essential for normal hematopoiesis, as demonstrated by defects in erythropoiesis observed in JAK2-deficient mice (27). It is composed of two main domains, one is an enzymatically active kinase domain (JAK homology 1; JH1) and the other consists of a catalytically inactive pseudokinase domain (JH2), which exerts an inhibitory affect that generally inhibits the kinase activity of JAK2 (27-29).

In MPN patients, even in the absence of the JAK 2 mutation, the other genetic changes result in activation of the JAK2 signaling pathway (30).

The most common mutation of JAK 2 consists of a substitution of valine with phenylalanine at position 617 in the $\mathrm{JH} 2$ domain (JAK2 V617F) in exon 14, which affects the inhibitory function of the pseudokinase $\mathrm{JH} 2$ domain, inducing an increased activity in myeloid progenitor cells, leading to proliferation and excessive production of mature cells (27,29,31-33). JAK2 V617F and exon 12 mutations signal through the same C-terminal tyrosine kinase of JAK2, but result in very different phenotypic readouts. JAK2 exon 12 mutations are tightly associated with PV in patients and mouse models (13). The reasons for these different abnormal phenotypic outcomes remain unclear and are likely to be complex $(34,35)$.

For the JAK2 V617F mutation to affect hematopoietic progenitor cells, the presence of receptors for erythropoietin, thrombopoietin or granulocyte-colony stimulating factor (CSF) is essential, leading to enhanced functional activity and increased sensitivity to cytokines and hematopoietic growth factors, such as interleukin 3 (IL-3), stem cell factor (SCF), granulocyte-macrophage CSF and insulin-like growth factor-1 (27).

Previous data demonstrate the contribution and influence of the presence of the JAK2 V617F mutation and the respective gene dosage in the definition of phenotype and prognostic impact in PN-MPNs (36). For example, the V617F allele burden tends to be higher in PV and PMF, and is associated with the presence of acquired uniparental disomy (UPD), whereas a lower allele burden is generally observed in ET patients $(7,16,33,37,38)$.
In PV and ET, risk factors for survival include older age, leukocytosis and thrombosis, whereas in ET, the JAK2 V617F mutation is associated with increased risk of thrombosis, and is incorporated into the International Prognostic Score for Thrombosis in ET-thrombosis score $(12,39)$. Accumulation of JAK2 mutated allele accompanies the transformation of PV and ET to secondary myelofibrosis (40). Furthermore, the presence of two or more mutations predicts a worse survival and is associated with shortened leukemia-free survival (41).

Furthermore, JAK2 V617F is not specific for a particular PN-MPN, nor does its absence exclude MPNs. Indeed, this has been reported in certain cases of MDS/MPN, in rare cases of AML (in combination with other well-defined genetic abnormalities, such as BCR-ABL1), and in association with certain solid tumors $(1,27,31,42-44)$.

A wider characterization of molecular genetic features in PN-MPNs may contribute to an improved knowledge and understanding of the physiopathology of these disorders, allowing achievement of novel specific diagnostic, prognostic and therapeutic tools $(20,45)$. The identification of JAK2/MPL mutations in the majority of patients led to the development of JAK kinase inhibitors. Although ruxolitinib was recently approved for use in hydroxyurea-resistant PV, its role in routine clinical practice remains controversial $(6,46-49)$. For myelofibrosis patients, stem cell transplant is the current treatment of choice for genetically or clinically high-risk disease. For all other patients that require treatment, the currently available drugs, including JAK inhibitors, are palliative, as they improve patient symptoms and reduce splenomegaly, but have not been identified as disease modifying, nor do they significantly reduce the mutant allele burden $(47,50)$.

The present study describes a hospital based case-control study to evaluate the prevalence of the JAK2 mutation in PN-MPNs patients, as well as in healthy individuals without clinical disease, in a Caucasian Portuguese population.

\section{Materials and methods}

Study subjects. The present study involved 133 Caucasian Portuguese PN-MPN patients (80 with ET, 39 with PV and 14 with PMF) and 281 age- and sex-matched control subjects selected since January 2009 to July 2016 within the Portuguese population recruited at the Departments of Clinical Hematology and of Clinical Pathology, Hospital de São Francisco Xavier, Centro Hospitalar de Lisboa Ocidental (CHLO; Lisbon, Portugal), a public general hospital that provides healthcare to the western population of Lisbon, where those patients were admitted, followed up and treated. The diagnostic criteria for all patients were those defined by the World Health Organization in the 2008 and updated 2016 guidelines $(1,2)$. For all cases, at least two control individuals ( $\mathrm{n}=281)$, without neoplastic pathology, matched for age ( \pm 2 years), gender and ethnicity were recruited, with no personal or family history of PN-MPNs, no previous or current malignant disease, nor history of blood transfusions. All study subjects were Portuguese, with Portuguese ascendants. Information on demographic characteristics, family history of cancer, lifestyle habits (e.g., smoking) and exposure to ionizing radiation was collected via a questionnaire administered by trained interviewers. With respect to smoking habits, former smokers were considered as non-smokers if they gave 
Table I. General characteristics of the Philadelphia-negative-myeloproliferative neoplasm cases ( $\mathrm{n}=133)$ and control population ( $n=281)$.

\begin{tabular}{|c|c|c|c|}
\hline Characteristic & Cases, n (\%) & Controls, n (\%) & P-value \\
\hline Sex & & & 0.8 \\
\hline Male & $61(45.9)$ & $133(47.3)$ & \\
\hline Female & $72(54.1)$ & $148(52.7)$ & \\
\hline Age, years ${ }^{a}$ & & & 0.6 \\
\hline $30-49$ & $16(12.0)$ & $43(15.3)$ & \\
\hline $50-69$ & $50(37.6)$ & $107(38.1)$ & \\
\hline$\geq 70$ & $67(50.4)$ & $131(46.6)$ & \\
\hline Smoking habits & & & 0.6 \\
\hline Never & $104(78.2)$ & $213(76.1)$ & \\
\hline Current & $29(21.8)$ & $67(23.9)$ & \\
\hline Alcohol habits & & & $<0.0001$ \\
\hline Never & $103(77.4)$ & $191(68.2)$ & \\
\hline Social & $20(15.0)$ & $25(8.9)$ & \\
\hline Regular & $10(7.5)$ & $64(22.9)$ & \\
\hline JAK2 V617F mutation & & & 0.020 \\
\hline Yes & $99(75.0)$ & & \\
\hline Essential thrombocythemia & $58(73.4)$ & & \\
\hline Polycythemia vera & $34(87.2)$ & & \\
\hline Primary myelofibrosis & $7(50.0)$ & & \\
\hline No & $33(25.0)$ & $281(100.0)$ & \\
\hline
\end{tabular}

${ }^{\mathrm{a}} \mathrm{Age}$ at diagnosis for the patients and age of the control population subjects at the time of diagnosis of the matched case.

Table II. Allelic distribution in the Philadelphia-negative myeloproliferative neoplasm cases $(n=133)$.

\begin{tabular}{lccc}
\hline $\begin{array}{l}\text { Janus kinase } 2 \\
\text { Diagnosis }\end{array}$ & $\begin{array}{c}\text { Val/val } \\
(\%)\end{array}$ & $\begin{array}{c}\text { Val/phe } \\
(\%)\end{array}$ & $\begin{array}{c}\text { Phe/phe } \\
(\%)\end{array}$ \\
\hline $\begin{array}{l}\text { Essential } \\
\text { thrombocythemia }\end{array}$ & $21(26.6)$ & $56(70.9)$ & $2(2.5)$ \\
$\begin{array}{l}\text { Polycythemia vera } \\
\begin{array}{l}\text { Primary } \\
\text { myelofibrosis }\end{array}\end{array}$ & $\begin{array}{l}5(12.8) \\
7(50.0)\end{array}$ & $\begin{array}{c}3(79.5) \\
5(35.7)\end{array}$ & $2(14.3)$ \\
\hline
\end{tabular}

Phe, phenylalanine; Val, valine.

up smoking either 2 years before PN-MPN diagnosis or, for controls, 2 years before the date of inclusion in the study. The response rate was $>95 \%$ for the cases and control subjects. The anonymity of the patients and control population was guaranteed, and written informed consent was obtained from all those involved, prior to blood withdrawal, in agreement with the Declaration of Helsinki. The current study was conducted with approval by the Institutional Ethics Boards of the involved institutions - CHLO and Nova Medical School (where the practical work was performed), both in Lisbon, Portugal.
The general characteristics for PN-MPNs patients at the time of diagnosis and the control populations are summarized in Tables I and II. All clinical and hematologic data were obtained from registries, and were selected on the basis of diagnostic criteria for this type of disease.

DNA extraction. Peripheral blood samples $(7-8 \mathrm{ml})$ of all patients and controls were collected by qualified personnel into $10 \mathrm{ml}$ EDTA tubes and maintained thereafter at $-80^{\circ} \mathrm{C}$. Genomic DNA was obtained from each blood sample $(250 \mu \mathrm{l})$ using a commercially available kit (QIAamp ${ }^{\circledR}$ DNA mini kit (cat. no. 51306); Qiagen GmbH, Hilden, Germany) according to the manufacturer's instructions. All DNA samples were stored at $-20^{\circ} \mathrm{C}$ until analysis.

Genotyping. The JAK2 V617F mutational status was determined via quantitative polymerase chain reaction (qPCR; Applied Biosystems 7300 Real-Time PCR System; Applied Biosystems; Thermo Fisher Scientific, Inc., Waltham, MA, USA), and TaqMan ${ }^{\circledR}$ single nucleotide polymorphism genotyping assay (rs77375493; cat. no. C_101301592_10, Thermo Fisher Scientific, Inc.), the methodology was performed according to the manufacturer's instructions with minor modifications which were also reported in our previous published papers (51-55). Briefly, to perform the PCR reaction, a final reaction volume of $10 \mu \mathrm{l}$ was used with the following thermocycling conditions: one step of enzyme activation at $95^{\circ} \mathrm{C}$ for 
10 min, followed by two cycling steps: A denaturation step at $95^{\circ} \mathrm{C}$ for $15 \mathrm{~min}$ and an annealing step at $60^{\circ} \mathrm{C}$ for $1 \mathrm{~min}$. Each PCR reaction required at least 40 cycles. The data analysis was performed using the fluorescence measurements made during the plate read, the SDS software plots $\mathrm{Rn}$ values based on the fluorescence signals from each well, then this determined which alleles are in each sample. Genotype determination was performed in $20 \%$ of samples in independent experiments and all of the inconclusive samples were reanalyzed.

Statistical analysis. The analysis of Hardy-Weinberg frequencies for all alleles in the control and patient populations was conducted using exact probability tests available at the SNPStat website software (http://bioinfo.iconcologia.net/SNPstats) (56). Differences in genotype frequency, smoking status, age ranges and gender distributions between PN-MPN cancer patients and control subjects were evaluated using the $\chi^{2}$ test. $\mathrm{P}<0.05$ was considered to indicate a statistically significant difference.

\section{Results}

The present study included 133 PN-MPN patients and 281 age- and sex-matched control subjects. The baseline characteristics (sex, age and smoking habits) of the case and control populations are presented in Table I. The case group included $72(54.1 \%)$ female and $61(45.9 \%)$ male patients, with an overall mean age of 68 years (Table I). No significant differences were identified between the case and control groups concerning age distribution or smoking habits (Table I).

According to the diagnostic criteria, the patient distributions were as follows: $80(60.2 \%)$ with ET, 39 (29.3\%) with PV and $14(10.5 \%)$ with PMF. The majority of the patients with ET were female (60.0\%), while in PV and PMF, males predominated (51.3 and 64.3\%, respectively; Table II).

Patient and control populations were stratified according to the presence of the JAK2 V617F mutation, demonstrating that $75.0 \%$ of patients and none of the controls were positive for JAK2 V617F (Table I). The prevalence of the JAK2 V617F mutation for patients with PV was $87.2 \%$, for ET $73.4 \%$ and for PMF $50.0 \%$ (Table II). The allelic distribution of the PN-MPN cases, stratified by diagnosis, is presented in Table II. General characteristics of patients are presented in Table II, according to the type of PN-MPN.

\section{Discussion}

In recent years, investigation on MPNs revealed that there are three driver mutations (JAK2, MPL and CALR) essential as clonal markers, activating the cytokine receptor JAK2 signaling pathway and the downstream effectors $(30,57)$.

However, it is known that the different driver mutations involved in the pathogenesis of MPNs leads to different clinical effects, and that a single mutation may be associated with distinct phenotypes and clinical outcomes. This finding may be due to the association with other commutated non-MPN-driver genes (for example, additional sex combs like 1, transcriptional regulator, enhancer of zeste 2 polycomb repressive complex 2 subunit, tet methylcytosine dioxygenase 2 , isocitrate dehydrogenase (NADP+)1/2, cytosolic, splicing factor 3 b subunit 1 , serine and arginine rich splicing factor 2) (57).
It is unequivocal that the JAK2 V617F mutation is found in various phenotypes; however, it is seemingly also associated with other malignancies (generally non-hematological types) (44).

The role of the JAK/STAT signaling pathway in the pathogenesis of MPNs and other cancers is questionable when considering the example of rare families presenting with germline mutations leading to weak JAK activation. The mutations originate a hereditary thrombocytosis, but hematopoiesis is polyclonal and there is no development of hematological malignancies or solid tumors, indicating that JAK/STAT activation alone does not drive malignant disease (43).

The JAK2 V617F mutation was screened in the patients and healthy control subjects, to evaluate the eventual presence and prevalence of the JAK2 mutation in healthy individuals in our control population, reflecting healthy Portuguese general population status, as it is the most prevalent among the driver mutations for PN-MPNs. The fact that no JAK2 V617F mutation was identified in healthy control subjects during the present study does not dismiss the possible weak effect of this mutation in driving MPNs. Although the absence of the JAK2 mutation does not exclude MPN, its presence is not specific for any specific PN-MPN and phenotypic expression may depend on various factors.

However, as the JAK2 V617F mutation is found in the great majority of MPNs indicates that it is probably the primary abnormality driving myeloproliferative cells, although it is not definitely clear whether it has to be homozygous in all cases; it may become homozygous as a result of the loss of heterozygosity $(\mathrm{LOH})$ or UPD $(33,58)$. Furthermore, it cannot be ruled out whether an inherited mutation in one of the alleles may be accompanied by an epigenomic inactivation of the other otherwise normal alleles rendering the cell biological homozygous. What seems clear, however, and the present data contributes to this conclusion, is that the role of the JAK2 V617F mutation in the pathogenicity of the different MPNs may differ amongst different MPNs requiring the JAK2 V617F mutation more often than others (e.g., ET vs. PV), which would indicate other oncogenic mutations that may be relevant for certain cases others than JAK2 V617F $(16,33,58,59)$.

Besides mutations and other molecular abnormalities, various factors, such as gene burden and individual genetic background, may influence the predisposition for developing an MPN, as well as their heterogeneity $(16,57)$. Although JAK2 V617F homozygous subclones are present in PV and ET patients, the expansion of a dominant homozygous subclone occurs almost exclusively in PV patients ( 80\% in PV and $50 \%$ in ET) $(33,57)$, due to either additional genetic or epigenetic events or non-cell-autonomous selective pressures, such as low levels of circulating erythropoietin in the context of elevated hematocrit (33).

However, the WHO classification of classical MPNs allows that the diagnosis is established on the basis of other criteria, even if the criteria concerning the driver mutations is not met, and that diagnosis is established on the basis of other criteria. Indeed, these disorders are primarily defined on the basis of clinical, pathologic and morphologic/histologic features, with the possibility of diagnosing MPN without any evidence of a driver mutation $(1,2)$. 
The present study revealed a higher incidence of the JAK2 V617F mutation in ET patients and a comparatively lower incidence in the PV patients, when compared with the published data for each disease $(6,7,14,15)$. The discrepancy between published data and the present results is greater in the case of ET, than in PV. This may be due to the small size of the investigated population and to the larger number of ET patients that was included. The majority of patients presented with ET ( 80 of a total of 133 patients), leading to a more consistent and representative result, reflecting Portuguese reality, when compared with PV. This indicates that the population of the present study has a different pattern concerning the presence of this mutation, when compared with other already studied populations from other countries, highlighting the importance of developing future studies in larger and diversified populations.

As described by Rumi and Cazzola (57), patients with the wild type JAK2 V617F or exon 12 mutation are extremely rare. However, the current results revealed a prevalence of $12.8 \%$ of patients with the wild type genotype. This finding supports the fact that the JAK2 mutation acting alone may not be sufficient to develop the PV phenotype. However, larger studies are required to confirm this hypothesis.

Subsequent to performing a literature review, almost all of the patients diagnosed with PV negative for the JAK2 V617F mutation were exon 12-positive (96 vs. $\sim 3 \%$, respectively) $(2,13,35,60-66)$. In the current study, from the five PV patients that were exon 14-negative, two underwent exon 12 molecular evaluation, and only one was positive. For certain patients, particularly those selected at the beginning of the study, it was no longer possible to obtain blood samples to proceed with the study.

CALR and MPL mutations were not assessed in the ET and MF patients that were JAK2-negative when the diagnosis was not doubtful, and therefore when the diagnosis was certain on the basis of clinical, pathologic and morphologic/histologic features. The presence of these mutations may therefore not be necessarily met criteria according to the WHO classification.

The patients and controls included in the present study were recruited from 2009 until 2016. The majority of the patients were evaluated according to the WHO 2008 diagnostic criteria, which was revised in 2016 (Table I). Although bone marrow biopsies may not be a met criterion (for ET and PV) in the two versions of the WHO classification, in our institution this is a type of routine examination for these patients, as it is considered to be important for predicting the prognosis.

Published epidemiology data are scarce $(3,4)$. The gender distribution observed in the current population was consistent with previous data regarding this group of disorders (67). Furthermore, although certain published studies consider smoking as a contributing factor for PN-MPNs $(68,69)$, the present study did not reveal a significant association, potentially due to the small number of smoking individuals that was included.

Additional studies involving larger populations are required to further clarify the potential value of different genotypes as predictive biomarkers of susceptibility to PN-MPNs. An improved understanding of the pathophysiological mechanisms will enable the development of drugs that are more directly and specifically targeted, with high efficacy and fewer adverse effects, thus contributing to the compliance of patients with treatments.

The discovery of JAK2 was a very important milestone for the studies that followed and for what is known today, but the ongoing identification of other mutations in MPNs will make possible the signaling of new drug targets and prognostic biomarkers that will for certain improve clinical practice and patients' outcome. In conclusion, it remains to be fully ascertained whether JAK2 mutations may considered as 'driver mutations' for MPNs, or if they can act as 'passenger mutations' which may change place with the former and have 'driver' functions (24).

\section{Acknowledgements}

The authors would like to thank all of the patients and control subjects who participated in the present study. The authors would also like to thank laboratory technicians Luísa Manso Oliveira and Inês Sousa for their expert technical assistance. The study was supported by funding from the Center for Toxicogenomics and Human Health (ToxOmics), from Fundação para a Ciência e Tecnologia (FCT), Portugal (grant no. UID/BIM/0009/2016). In addition, a BPD grant from FCT was awarded to Dr Silva (grant no. SFRH/BPD/ 80462/2011).

\section{References}

1. Swerdlow SH, Campo E, Harris NL, Jaffe ES, Pileri SA, Stein H, Thiele J and Vardiman JW: WHO Classification of Tumours of Haematopioetic and Lymphoid Tissues. World Health Organization, Lyon, 2008.

2. Arber DA, Orazi A, Hasserjian R, Thiele J, Borowitz MJ, Le Beau MM, Bloomfield CD, Cazzola M and Vardiman JW: The 2016 revision to the World Health Organization classification of myeloid neoplasms and acute leukemia. Blood 127: 2391-2405, 2016.

3. Titmarsh GJ, Duncombe AS, McMullin MF, O'Rorke M, Mesa R, De Vocht F, Horan S, Fritschi L, Clarke M and Anderson LA: How common are myeloproliferative neoplasms? A systematic review and meta-analysis. Am J Hematol 89: 581-587, 2014.

4. Moulard O, Mehta J, Fryzek J, Olivares R, Iqbal U and Mesa RA: Epidemiology of myelofibrosis, essential thrombocythemia, and polycythemia vera in the European Union. Eur J Haematol 92: 289-297, 2014.

5. Cross NC: Genetic and epigenetic complexity in myeloproliferative neoplasms. Hematology (Am Soc Hematol Educ Program) 2011: 208-214, 2011.

6. Tefferi A and Pardanani A: Myeloproliferative Neoplasms: A Contemporary Review. JAMA Oncol 1: 97-105, 2015.

7. Duletić AN, Dekanić A, Hadzisejdić I, Kusen I, Matusan-Ilijas K, Grohovac D, Grahovac B and Jonjić N: JAK2-v617F mutation is associated with clinical and laboratory features of myeloproliferative neoplasms. Coll Antropol 36: 859-865, 2012.

8. Tefferi A and Vardiman JW: Classification and diagnosis of myeloproliferative neoplasms: The 2008 World Health Organization criteria and point-of-care diagnostic algorithms. Leukemia 22: 14-22, 2008.

9. James C, Ugo V,Le Couédic JP, Staerk J, Delhommeau F, Lacout C, Garçon L, Raslova H, Berger R, Bennaceur-Griscelli A, et al: A unique clonal JAK2 mutation leading to constitutive signalling causes polycythaemia vera. Nature 434: 1144-1148, 2005.

10. Kralovics R, Passamonti F, Buser AS, Teo SS, TiedtR, Passweg JR, Tichelli A, Cazzola M and Skoda RC: A gain-of-function mutation of JAK2 in myeloproliferative disorders. N Engl J Med 352: 1779-1790, 2005.

11. Levine RL, Wadleigh M, Cools J, Ebert BL, Wernig G, Huntly BJ, Boggon TJ, Wlodarska I, Clark JJ, Moore S, et al: Activating mutation in the tyrosine kinase JAK2 in polycythemia vera, essential thrombocythemia, and myeloid metaplasia with myelofibrosis. Cancer Cell 7: 387-397, 2005. 
12. Baxter EJ, Scott LM, Campbell PJ, East C, Fourouclas N, Swanton S, Vassiliou GS, Bench AJ, Boyd EM and Curtin N; Cancer Genome Project: Acquired mutation of the tyrosine kinase JAK2 in human myeloproliferative disorders. Lancet 365: 1054-1061, 2005.

13. Scott LM, Tong W, Levine RL, Scott MA, Beer PA, Stratton MR, Futreal PA, Erber WN, McMullin MF, Harrison CN, et al: JAK2 exon 12 mutations in polycythemia vera and idiopathic erythrocytosis. N Engl J Med 356: 459-468, 2007.

14. Nangalia J, Massie CE, Baxter EJ, Nice FL, Gundem G, Wedge DC, Avezov E, Li J, Kollmann K, Kent DG, et al: Somatic CALR mutations in myeloproliferative neoplasms with nonmutated JAK2. N Engl J Med 369: 2391-2405, 2013

15. Levine RL: Mechanisms of mutations in myeloproliferative neoplasms. Best Pract Res Clin Haematol 22: 489-494, 2009.

16. Hinds DA, Barnholt KE, Mesa RA, Kiefer AK, Do CB Eriksson N, Mountain JL, Francke U, Tung JY, Nguyen HM, et al: Germ line variants predispose to both JAK2 V617F clonal hematopoiesis and myeloproliferative neoplasms. Blood 128: $1121-1128,2016$

17. Cazzola M and Kralovics R: From Janus kinase 2 to calreticulin: The clinically relevant genomic landscape of myeloproliferative neoplasms. Blood 123: 3714-3719, 2014

18. Oh ST and Gotlib J: JAK2 V617F and beyond: Role of genetics and aberrant signaling in the pathogenesis of myeloproliferative neoplasms. Expert Rev Hematol 3: 323-337, 2010.

19. Bolufer P, Barragan E, Collado M, Cervera J, López JA and Sanz MA: Influence of genetic polymorphisms on the risk of developing leukemia and on disease progression. Leuk Res 30 : 1471-1491, 2006

20. Delhommeau F, Jeziorowska D, Marzac C and Casadevall N: Molecular aspects of myeloproliferative neoplasms. Int $\mathrm{J}$ Hematol 91: 165-173, 2010.

21. Beer PA, Delhommeau F, LeCouédic JP, Dawson MA, Chen E, Bareford D, Kusec R, McMullin MF, Harrison CN, Vannucchi AM, et al: Two routes to leukemic transformation after a JAK2 mutation-positive myeloproliferative neoplasm. Blood 115: 2891-2900, 2010.

22. Kilpivaara $\mathrm{O}$ and Levine RL: JAK 2 and MPL mutations in myeloproliferative neoplasms: Discovery and science. Leukemia 22 1813-1817, 2008

23. Björkholm M, Hultcrantz M and Derolf ÅR: Leukemic transformation in myeloproliferative neoplasms: Therapy-related or unrelated? Best Pract Res Clin Haematol 27: 141-153, 2014

24. Rueff J and Rodrigues AS: Cancer Drug Resistance: A Brief Overview from a Genetic Viewpoint. Methods Mol Biol 1395: $1-18,2016$.

25. Rice KL, Lin X, Wolniak K, Ebert BL, Berkofsky-Fessler W, Buzzai M, Sun Y, Xi C, Elkin P, Levine R, et al: Analysis of genomic aberrations and gene expression profiling identifies novel lesions and pathways in myeloproliferative neoplasms. Blood Cancer J 1: e40, 2011.

26. Campregher PV, Santos FP, Perini GF and Hamerschlak N: Molecular biology of Philadelphia-negative myeloproliferative neoplasms. Rev Bras Hematol Hemoter 34: 150-155, 2012.

27. Ebid GT, Ghareeb M, Salaheldin O and Kamel MM: Prevalence of the frequency of JAK2 (V617F) mutation in different myeloproliferative disorders in Egyptian patients. Int J Clin Exp Pathol 8: 11555-11559, 2015.

28. Jatiani SS, Baker SJ, Silverman LR and Reddy EP: Jak/STAT pathways in cytokine signaling and myeloproliferative disorders: Approaches for targeted therapies. Genes Cancer 1: 979-993, 2010

29. Anand S, Stedham F, Beer P, Gudgin E, Ortmann CA, Bench A Erber W, Green AR and Huntly BJ: Effects of the JAK2 mutation on the hematopoietic stem and progenitor compartment in human myeloproliferative neoplasms. Blood 118: 177-181, 2011

30. Reuther GW: Myeloproliferative Neoplasms: Molecular Drivers and Therapeutics. Prog Mol Biol Transl Sci 144: 437-484, 2016.

31. Steensma DP, McClure RF, Karp JE, Tefferi A, Lasho TL, Powell HL, DeWald GW and Kaufmann SH: JAK2 V617F is a rare finding in de novo acute myeloid leukemia, but STAT3 activation is common and remains unexplained. Leukemia 20: 971-978, 2006.

32. Green DR and Llambi F: Cell Death Signaling. Cold Spring Harb Perspect Biol 7: 7, 2015

33. Chen E and Mullally A: How does JAK2V617F contribute to the pathogenesis of myeloproliferative neoplasms? Hematology (Am Soc Hematol Educ Program) 2014: 268-276, 2014

34. Godfrey AL, Chen E, Massie CE, Silber Y, Pagano F, Bellosillo B, Guglielmelli P, Harrison CN, Reilly JT, Stegelmann F, et al STAT1 activation in association with JAK2 exon 12 mutations. Haematologica 101: e15-e19, 2016
35. Passamonti F, Elena C, Schnittger S, Skoda RC, Green AR, Girodon F, Kiladjian JJ, McMullin MF, Ruggeri M, Besses C, et al: Molecular and clinical features of the myeloproliferative neoplasm associated with JAK2 exon 12 mutations. Blood 117: 2813-2816, 2011

36. Nielsen C, Bojesen SE, Nordestgaard BG, Kofoed KF and Birgens HS: JAK2V617F somatic mutation in the general population: Myeloproliferative neoplasm development and progression rate. Haematologica 99: 1448-1455, 2014.

37. Ha JS, Kim YK, Jung SI, Jung HR and Chung IS: Correlations between Janus kinase 2 V617F allele burdens and clinicohematologic parameters in myeloproliferative neoplasms. Ann Lab Med 32: 385-391, 2012.

38. Larsen TS, Pallisgaard N, Møller MB and Hasselbalch HC The JAK2 V617F allele burden in essential thrombocythemia, polycythemia vera and primary myelofibrosis - impact on disease phenotype. Eur J Haematol 79: 508-515, 2007.

39. BarbuiT, Vannucchi AM,Buxhofer-Ausch V,De Stefano V,BettiS, Rambaldi A, Rumi E, Ruggeri M, Rodeghiero F, Randi ML, et al: Practice-relevant revision of IPSET-thrombosis based on 1019 patients with WHO-defined essential thrombocythemia. Blood Cancer J 5: e369, 2015.

40. Vannucchi AM, Pieri L and Guglielmelli P: JAK2 Allele Burden in the Myeloproliferative Neoplasms: Effects on Phenotype, Prognosis and Change with Treatment. Ther Adv Hematol 2: 21-32, 2011.

41. Guglielmelli P, Lasho TL, Rotunno G, Score J, Mannarelli C, Pancrazzi A, Biamonte F, Pardanani A, Zoi K, Reiter A, et al: The number of prognostically detrimental mutations and prognosis in primary myelofibrosis: An international study of 797 patients. Leukemia 28: 1804-1810, 2014.

42. Vainchenker W and Constantinescu SN: JAK/STAT signaling in hematological malignancies. Oncogene 32: 2601-2613, 2013.

43. Thomas SJ, Snowden JA, Zeidler MP and Danson SJ: The role of JAK/STAT signalling in the pathogenesis, prognosis and treatment of solid tumours. Br J Cancer 113: 365-371, 2015.

44. Nielsen C, Birgens HS, Nordestgaard BG, Kjaer L and Bojesen SE: The JAK2 V617F somatic mutation, mortality and cancer risk in the general population. Haematologica 96: 450-453, 2011

45. Mambet C, Matei L, Necula LG and Diaconu CC: A link between the driver mutations and dysregulated apoptosis in BCR-ABL1 negative myeloproliferative neoplasms. J Immunoassay Immunochem 37: 331-345, 2016.

46. Tefferi A and Barbui T: Polycythemia vera and essential thrombocythemia: 2017 update on diagnosis, risk-stratification, and management. Am J Hematol 92: 94-108, 2017.

47. Tefferi A: Myeloproliferative neoplasms: A decade of discoveries and treatment advances. Am J Hematol 91: 50-58, 2016.

48. Hobbs GS, Rozelle S and Mullally A: The Development and Use of Janus Kinase 2 Inhibitors for the Treatment of Myeloproliferative Neoplasms. Hematol Oncol Clin North Am 31: 613-626, 2017.

49. Vannucchi AM and Harrison CN: Emerging treatments for classical myeloproliferative neoplasms. Blood 129: 693-703, 2017.

50. Stahl M and Zeidan AM: Management of myelofibrosis: JAK inhibition and beyond. Expert Rev Hematol 10: 459-477, 2017.

51. Silva SN, Moita R, Azevedo AP, Gouveia R, Manita I, Pina JE, Rueff J and Gaspar J: Menopausal age and XRCC1 gene polymorphisms: Role in breast cancer risk. Cancer Detect Prev 31: 303-309, 2007

52. Bastos HN, Antão MR, Silva SN, Azevedo AP, Manita I, Teixeira V, Pina JE, Gil OM, Ferreira TC, Limbert E, et al: Association of polymorphisms in genes of the homologous recombination DNA repair pathway and thyroid cancer risk. Thyroid 19: 1067-1075, 2009.

53. Conde J, Silva SN, Azevedo AP, Teixeira V, Pina JE, Rueff J and Gaspar JF: Association of common variants in mismatch repair genes and breast cancer susceptibility: A multigene study. BMC Cancer 9: 344, 2009

54. Gomes BC, Silva SN, Azevedo AP, Manita I, Gil OM, Ferreira TC, Limbert E, Rueff J and Gaspar JF: The role of common variants of non-homologous end-joining repair genes XRCC4, LIG4 and Ku80 in thyroid cancer risk. Oncol Rep 24: 1079-1085, 2010.

55. Silva SN, Azevedo AP, Teixeira V, Pina JE, Rueff J and Gaspar JF: The role of GSTA2 polymorphisms and haplotypes in breast cancer susceptibility: A case-control study in the Portuguese population. Oncol Rep 22: 593-598, 2009.

56. Solé X, Guinó E, Valls J, Iniesta R and Moreno V: SNPStats: A web tool for the analysis of association studies. Bioinformatics 22: 1928-1929, 2006

57. Rumi E and Cazzola M: Diagnosis, risk stratification, and response evaluation in classical myeloproliferative neoplasms. Blood 129: 680-692, 2017. 
58. Jones AV, Kreil S, Zoi K, Waghorn K, Curtis C, Zhang L, Score J, Seear R, Chase AJ, Grand FH, et al: Widespread occurrence of the JAK2 V617F mutation in chronic myeloproliferative disorders. Blood 106: 2162-2168, 2005.

59. Lundberg P, Takizawa H, Kubovcakova L, Guo G Hao-Shen H, Dirnhofer S, Orkin SH, Manz MG and Skoda RC: Myeloproliferative neoplasms can be initiated from a single hematopoietic stem cell expressing JAK2-V617F. J Exp Med 211: 2213-2230, 2014

60. Butcher CM, Hahn U, To LB, Gecz J, Wilkins EJ, Scott HS, Bardy PG and D'Andrea RJ: Two novel JAK2 exon 12 mutations in JAK2V617F-negative polycythaemia vera patients. Leukemia 22: 870-873, 2008

61. Park CH, Lee KO, Jang JH, Jung CW, Kim JW, Kim SH and Kim HJ: High frequency of JAK2 exon 12 mutations in Korean patients with polycythaemia vera: Novel mutations and clinical significance. J Clin Pathol 69: 737-741, 2016.

62. Passamonti F, Rumi E, Pietra D, Elena C, Boveri E, Arcaini L, Roncoroni E, Astori C, Merli M, Boggi S, et al: A prospective study of 338 patients with polycythemia vera: The impact of JAK2 (V617F) allele burden and leukocytosis on fibrotic or leukemic disease transformation and vascular complications. Leukemia 24: 1574-1579, 2010.

63. Rumi E, Pietra D, Ferretti V, Klampfl T, Harutyunyan AS Milosevic JD, Them NC, Berg T, Elena C, Casetti IC, et al; Associazione Italiana per la Ricerca sul Cancro Gruppo Italiano Malattie Mieloproliferative Investigators: JAK2 or CALR mutation status defines subtypes of essential thrombocythemia with substantially different clinical course and outcomes. Blood 123: 1544-1551, 2014.
64. Scott LM: The JAK2 exon 12 mutations: A comprehensive review. Am J Hematol 86: 668-676, 2011.

65. Scott LM, Beer PA, Bench AJ, Erber WN and Green AR: Prevalance of JAK2 V617F and exon 12 mutations in polycythaemia vera. Br J Haematol 139: 511-512, 2007.

66. Pardanani A, Lasho TL, Finke C, Hanson CA and Tefferi A Prevalence and clinicopathologic correlates of JAK2 exon 12 mutations in JAK2V617F-negative polycythemia vera. Leukemia 21: 1960-1963, 2007.

67. Azevedo AP, Silva SN, De Lima JP, Reichert A, Lima F, Júnior E and Rueff J: DNA repair genes polymorphisms and genetic susceptibility to Philadelphia-negative myeloproliferative neoplasms in a Portuguese population: The role of base excision repair genes polymorphisms. Oncol Lett 13: 4641-4650, 2017.

68. Lindholm Sørensen A and Hasselbalch HC: Smoking and philadelphia-negative chronic myeloproliferative neoplasms. Eur J Haematol 97: 63-69, 2015.

69. Hasselbalch HC: Smoking as a contributing factor for development of polycythemia vera and related neoplasms. Leuk Res 15: 30373-30378, 2015 